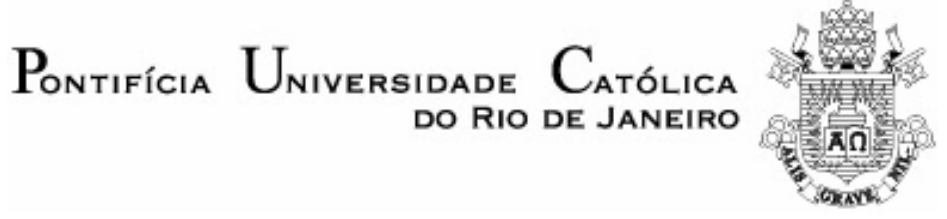

Rosana Corrêa Lobo

\begin{abstract}
AMORES EXPRESSOS: narrativas do não-pertencimento
\end{abstract}

Dissertação de Mestrado

Dissertação apresentada ao Programa de Pós-graduação em Letras do Departamento de Letras da PUC-Rio como parte dos requisitos parciais para a obtenção do título de Mestre em Letras.

Orientador: Prof. Renato Cordeiro Gomes

Rio de Janeiro

Março de 2010 
Rosana Corrêa Lobo

\section{Amores Expressos: narrativas do não-pertencimento}

Dissertação apresentada como requisito parcial para obtenção do grau de Mestre pelo programa de Pós-graduação em Letras do Departamento de Letras do Centro de Teologia e Ciências Humanas da PUC-Rio. Aprovada pela Comissão Examinadora

Prof. Renato Cordeiro Gomes Orientador

Departamento de Letras - PUC-Rio

Profa. Giovanna Ferreira Dealtry Departamento de Comunicação - PUC-Rio

Profa. Stefania Chiarelli Techima UFF

Prof. Paulo Fernando Carneiro de Andrade Coordenador Setorial do Centro de Teologia e Ciências Humanas - PUC-Rio

Rio de Janeiro, 13 de março de 2010 
Todos os direitos reservados. É proibida a reprodução total ou parcial do trabalho sem a autorização da autora, do orientador e da universidade.

\section{Rosana Corrêa Lobo}

Graduou-se em Comunicação Social - Radialismo na UFRJ (Universidade Federal do Rio de Janeiro) em 2003. Cursou pós-graduação lato sensu em Jornalismo Cultural na UERJ (Universidade Estadual do Rio de Janeiro) entre 2004 e 2005. Ingressou em 2008 no Programa de Pós-Graduação stricto sensu em Letras (Estudos de Literatura Brasileira) da PUCRio (Pontifícia Universidade Católica do Rio de Janeiro).

Ficha catalográfica

Lobo, Rosana Corrêa

Amores expressos : narrativas do nãopertencimento / Rosana Corrêa Lobo ; orientador: Renato Cordeiro Gomes. - 2010.

$93 \mathrm{f}$. ; $30 \mathrm{~cm}$

Dissertação(Mestrado)-Pontifícia Universidade Católica do Rio de Janeiro, Departamento de Letras, Rio de Janeiro, 2010.

Inclui bibliografia

1. Letras - Teses. 2. Identidade nacional. 3. Amores Expressos. 4. Galera, Daniel. 5. Carvalho, Bernardo. 6. Ruffato, Luiz, 1961-. I. Gomes, Renato Cordeiro. II. Pontifícia Universidade Católica do Rio de Janeiro. Departamento de Letras. III. Título.

CDD: 800 
Ao Cássio pela leitura atenta desse trabalho; à Alice por existir e à Adriana por cuidar de nós três. 


\section{Agradecimentos}

Ao meu orientador Renato Cordeiro Gomes, por ter acolhido o meu projeto e ter visto com tanta clareza a forma que ele deveria ter. Minha gratidão, carinho e admiração.

Aos meus pais e irmãos pelo incentivo.

A todos os professores que vêm contribuindo para minha formação em especial a Ana Arruda Callado, Leila Longo, Marília Rothier Cardoso e Vera Follain de Figueiredo pela seriedade e generosidade com que passam seus ensinamentos.

À Capes, ao CNPq e à PUC-Rio pelos auxílios concedidos para realização deste trabalho. 


\section{Resumo}

Lobo, Rosana Corrêa; Gomes, Renato Cordeiro. Amores Expressos: narrativas do não-pertencimento. Rio de Janeiro: 2010. 93p. Dissertação de Mestrado. Departamento de Letras. Pontifícia Universidade Católica do Rio de Janeiro.

Investigação de como se configura hoje a representação do imaginário nacional na literatura brasileira - cujos momentos altos foram o Romantismo e o Modernismo - e pensar se ocorre um possível fim deste ciclo, uma vez que, como parece indicar o projeto Amores Expressos (Companhia das Letras / RT Features), a nação já não ocupa mais o centro de um sistema de significação na nossa literatura. Busca-se ver como nos primeiros romances já publicados pelo projeto - Cordilheira (2008), de Daniel Galera, O filho da mãe (2009), de Bernardo Carvalho e Estive em Lisboa e lembrei de você (2009), de Luiz Ruffato, ambientados respectivamente em Buenos Aires, São Petersburgo e Lisboa - a representação da realidade local e de uma identidade unificada e homogênea abre espaço para uma representação cosmopolita de um mundo cujas identidades estão em crise.

\section{Palavras chave}

Identidade nacional; Amores Expressos; Daniel Galera; Bernardo Carvalho; Luiz Ruffato. 


\section{Abstract}

Lobo, Rosana Corrêa; Gomes, Renato Cordeiro (Advisor). Amores Expressos: not belonging narratives. Rio de Janeiro: 2010. 93p. Dissertação de Mestrado. Departamento de Letras. Pontifícia Universidade Católica do Rio de Janeiro.

This abstract presents an investigation of how the representation of the national image is established in brazilian literature, a period in literature when Romanticism and Modernism were the most remarkable. My aim is to investigate if it is possible to have closure to this cycle, since the project Amores Expressos (Companhia das Letras/RT Features) seems to indicate, the nation no longer occupies the center of a signifying system in our literature. The idea is to examine in the first novels published by the project - Cordilheira - (2008), by Daniel Galera, O filho da mãe (2009), by Bernardo Carvalho, and Estive em Lisboa e lembrei de você (2009), by Luiz Ruffato, which are set, respectively in Buenos Aires, Saint Petersburg and Lisbon.how the representation of the local reality and of a unified and homogeneous identity make space for a cosmopolitan representation of a world in which identities are going through a crisis.

\section{Keywords}

National identity; Amores Expressos; Daniel Galera; Bernardo Carvalho; Luiz Ruffato. 


\section{Sumário}

$\begin{array}{ll}\text { 1. Introdução } & 10\end{array}$

2. A escrita da nação 15

2.1. A invenção da nação na literatura brasileira 21

2.2. Globalização ou a 'desinvenção' da nação 31

3. Amores Expressos e a patrulha literária 36

3.1. Relatos de viagem e a condição de estrangeiro 44

4. Amores Expressos: narrativas do não-pertencimento 56

4.1. Cordilheira: uma narrativa de fronteira 56

4. 2. O filho da mãe: em busca de um lugar mais habitável 64

4.3. Estive em Lisboa e lembrei de você:

imigração, desenraizamento e desterritorialização além mar 71

4.4. Comunidades em ruínas 78

5. Considerações finais 82

6. Bibliografia 88 
Talvez todos nós estejamos, nos tempos modernos - após a expulsão do paraíso, digamos - no que o filósofo Heidegger chamou de unheimlicheit literalmente 'não estamos em casa'.

Stuart Hall, em Da diáspora: identidades $e$ meditações culturais 